\title{
STUDIES ON IN VITRO EVALUATION OF ANTIDIABETIC POTENTIALS OF WATERMELLON AND POMEGRANATE PEELS
}

\begin{abstract}
*Sani, S.B. and Nair, S. S.
Department of Biology, Kano University of Science and Technology, Wudil , P.M.B 3244 Kano-Nigeria Armat Biotek Training and Research Institute Guindy Chennai-600032, India

*Correspondence author: sakinasanibuhari@yahoo.com

ABSTRACT

Diabetes is a metabolic disorder which results due to deficiency in insulin and its metabolism. At present, the prevalence of Diabetes has increased worldwide and predicted to increase to greater extent in future generations. Among various therapeutic approaches implemented to prevent diabetes is to regulate the blood glucose levels by various mechanisms. This is being assessed by in vitro antidiabetic assays such as inhibition of carbohydrate digesting enzymes and non-enzymatic glycosylation of haemoglobin. Inhibition of alpha-amylase enzyme suppresses the level of production of glucose and by inhibiting glycosylation of haemoglobin the level of blood glucose is maintained. Hence the current work focuses on investigating the anti-diabetic activity of fruit peel of Citrullus lanatus (watermelon) and Punica granatum (pomegranate) using the above mentioned assays. Our results suggested that methanol extract of Citrullus lanatus and Punica granatum peels showed potential anti-diabetic activity in vitro which indicates that these extracts can be taken further for in vivo studies.

Keywords: fruit peels, antidiabetic activity, a-amylase enzyme, glycosylated haemoglobin
\end{abstract}

\section{INTRODUCTION}

Diabetes mellitus (DM) commonly referred to as diabetes has become a major health challenge worldwide (King et al. 1998); it is an endocrine disorder that affects the metabolism of carbohydrates, protein and fats. In 2012, an estimated 387 million people have diabetes worldwide with type 2 diabetes making up to about $90 \%$ of the cases (Shi and Hu, 2012). The number of people with diabetes is expected to rise to 592 million by 2035 (Vos et al., 2012). Learning about diabetes and participating in the treatment is vital for people with the disease. Type 1 diabetes must be managed with insulin injection (Kitabchi et al., 2009.). Type2 diabetes may be treated with medications such as metformin, glinatides, sulfonylureas, without insulin injection. But most of these synthetic drugs are associated with side effects such as weight gain, hypoglycaemia, gastrointestinal (GI) disturbances and liver injury (Bastaki, 2005). Hence, there is a need for natural product to treat diabetes with little or no side effects.

One of the effective method to control diabetes is to inhibit the activity of alpha amylase enzyme which is responsible for the breakdown of starch to more simple sugars (maltose, maltotriose, maltose and glucose). This is contributed by alpha amylase inhibitors. Medicinal plants have been reported to play an important role in inhibiting a- amylase activity due to the presence of aamylase inhibitors which prevent or delays the absorption of starch into the body thereby maintaining the serum blood glucose level (Dineshkumar et al., 2010).

In addition to the approaches, lowering glycosylated hemoglobin is vital in controlling diabetic related complications such retinopathy, neuropathy and cardiovascular diseases. The hemoglobin present in the red blood corpuscles has a tendency to get bound to glucose and form an abduct Alc. The greater the blood-glucose concentration, the greater is the amount of glucose-bound (called glycosylated) hemoglobin. Thus, the amount of glycosylated haemoglobin is a sure guide to the concentration of glucose in the blood. Amount of Glycated hemoglobin should not be more than 12\% (Daksha et al., 2012).

Watermelon (Citrullus lanatus) belongs to the family Cucurbitaceae is a flowering plant originally from South Africa. The fruit of this plant has a smooth hard rind, usually green with dark green stripes or yellow spots, and a juicy, sweet interior flesh, usually deep pink, but sometimes orange, yellow, or white, with many seeds. As with many other fruits, it is a source of vitamin C. Watermelon rind (peel), usually a light green or pale green color, are also edible and contain many hidden nutrients, but most people avoid eating them due to their unappealing flavor (Pouryazdi and Far, 1995). 
Pomegranate, botanical name Punica granatum, belongs to the family Punicaceae is a fruit-bearing deciduous shrub or small tree growing between five and eight meters tall and mainly found in Iran, the Himalayas in northern India, China and throughout the Mediterranean region. Punica granatum can be divided into several anatomical compartments including seed, juice, peel, leaf, flower, bark, and root with each possessing interesting pharmacological and toxicological activities including antioxidant, anti-inflammatory, anti microbial and anti cancer (Ismail et al., 2012). With this background information, the current study was intended to assess the antidiabetic potential of Watermelon (Citrullus lanatus) and pomegranate (Punica granatum) peel extracts.

\section{MATERIALS AND METHODS}

Sample collection and extraction

The present study was conducted at Armat Biotek Training and Research Institute Guindy Chennai-600032, India. Fresh peels of watermelon, and pomegranate were collected from local market, Chennai, Tamil Nadu. The shade dried peel powders were extracted with methanol by maceration method and the extracts were concentrated to yield a crude extract. The extractes were weighed and redissolved in Di methyl sulfoxide (DMSO) to yield $10 \mathrm{mg} / \mathrm{ml}$ solutions ready for further analysis.

\section{Inhibition of a-amylase activity}

The assay was carried out following the standard protocol (Kim et al., 2000) with slight modifications. Starch azure (2mg) was suspended in $0.2 \mathrm{ml}$ of $0.5 \mathrm{M}$ Tris- $\mathrm{HCl}$ buffer $(\mathrm{pH}$ 6.9) containing $0.01 \quad \mathrm{M} \mathrm{CaCl} 2$ (substrate solution). The tubes containing substrate solution were boiled for $10 \mathrm{~min}$ and then preincubated at $37^{\circ} \mathrm{C}$ for $5 \mathrm{~min}$. The extracts were dissolved in DMSO in concentrations of 20, 40, 60,80 , and $100 \mu \mathrm{g} / \mathrm{ml}$. Then, plant extracts was added to the tube containing the substrate solution. In addition, $0.2 \mathrm{ml}$ of porcine pancreatic a-amylase in Tris- $\mathrm{HCl}$ buffer (2units $/ \mathrm{ml}$ ) was added to the tube containing the plant extract and substrate solution. The reaction was carried out at $37^{\circ} \mathrm{C}$ for $10 \mathrm{~min}$. The reaction was stopped by adding $0.5 \mathrm{ml}$ of $50 \%$ acetic acid in each tube. The reaction mixture was centrifuged at $3000 \mathrm{rpm}$ for $5 \mathrm{~min}$ at $4^{\circ} \mathrm{C}$. The absorbance of resulting supernatant was measured at $595 \mathrm{~nm}$ using spectrophotometer (Perkin Elmer Lambda 25 UV-VIS spectrophotometer). The experiments were repeated thrice. Acarbose was used as a standard alpha-amylase inhibitor and percentage inhibition was calculated using the formula;

Inhibition $\%=$ Abs control - Abs sample $\times 100$

$$
\text { Abs control }
$$

Where, Abs control is the absorbance of the control reaction (containing all reagents except the test sample), and Abs sample is the absorbance of the test sample (Nair et al., 2013).

Non-enzymatic glycosylation of Haemoglobin

Glucose (2\%), haemoglobin (0.06\%) and Gentamycin $(0.02 \%)$ solutions were prepared in phosphate buffer $(0.01 \mathrm{M})$ at $\mathrm{pH}$ 7.4. About 1 $\mathrm{ml}$ each of above solution was mixed in a test tube. The methanolic extract was weighed and dissolved in DMSO to obtain stock solution and then $20-100 \mu \mathrm{g} / \mathrm{ml}$ solutions were prepared and then made up to $1 \mathrm{ml}$ by adding DMSO. Then 1 $\mathrm{ml}$ of each concentration was added to above mixture. The Mixture was incubated in dark at room temperature for $72 \mathrm{hrs}$ (Abirami et al., 2014). The degree of glycosylation of haemoglobin was measured calorimetrically at $520 \mathrm{~nm}$ (Daksha et al., 2012). Acarbose was used as a standard alpha amylase inhibitor and percentage inhibition was calculated using the formula;

$$
\% \text { inhibition }=\frac{\text { (Abs contral }- \text { AbsSample) }}{\text { AbsCantral }} \times 100
$$

Where, Abs control is the absorbance of the control reaction (containing all reagents except the test sample), and Abs sample is the absorbance of the test sample (Nair et al., 2013).

RESULTS AND DISCUSSION

Alpha-amylase inhibition method

a- amylase enzyme plays a vital role in the carbohydrate digestion. One of the good ways to regulate blood glucose level is through the inhibition of a- amylase activity there by maintaining blood glucose level. In our study, the methanol extract of watermelon and pomegranate showed high a- amylase inhibition percentage of 69 and 56 at a concentration of $100 \mu \mathrm{g} / \mathrm{ml}$ respectively. A recent study by Poojari and co-workers (2014) on methanol extract of Physalis angulata fruit reports aamylase inhibition percentage of 97 at $100 \mu \mathrm{g} / \mathrm{ml}$. Kumar (2015) also reported aamylase inhibition percentage of 57 at $1000 \mu \mathrm{g} / \mathrm{ml}$ in Pithecellobium dulce fruit peel. 


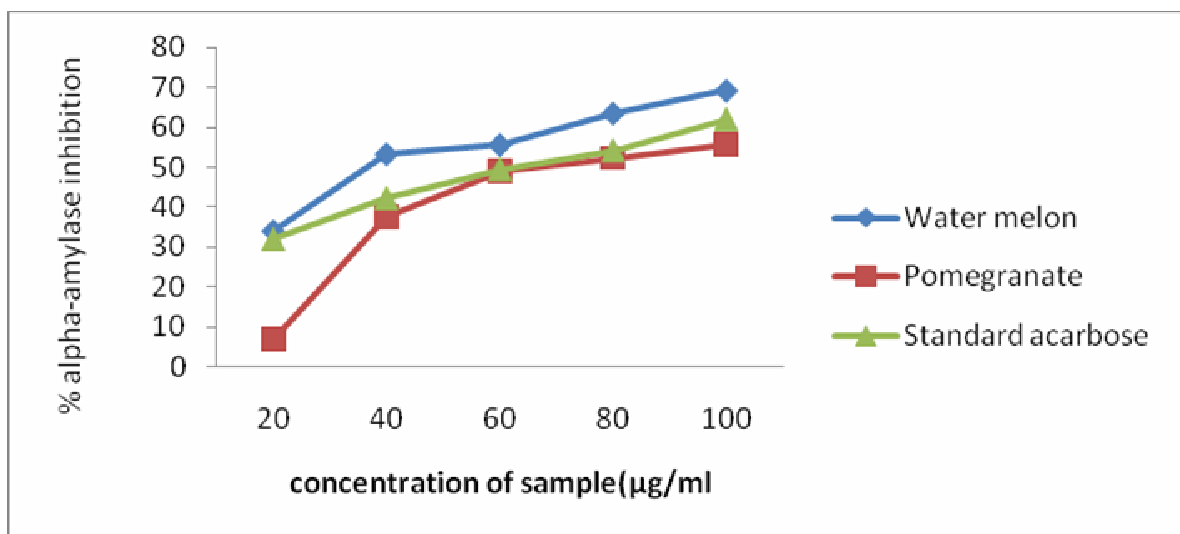

Figure 1: Inhibitory effect of watermelon and pomegranate extracts on a-amylase activity in comparison with acarbose

Percentage alpha-amylase inhibition was plotted in comparison with standard acarbose as dipicted in figure 1 . This result indicated that watermelon peel extract exhibited significant inhibition activity than the pomegranate extract in comparison with the standard acarbose. Acarbose inhibited the alpha-amylse activity with an IC50 value of $80.5 \mu \mathrm{g} / \mathrm{ml}$ at a concentration of $100 \mu \mathrm{g} / \mathrm{ml}$ while the IC50 values of watermelon and pomegranate peels extract was found to be $72.15 \mu \mathrm{g} / \mathrm{ml}$ and $89.8 \mu \mathrm{g} / \mathrm{ml}$ respectively at a concentration of $100 \mu \mathrm{g} / \mathrm{ml}$. The alpha-amylase inhibitory activity of all the extracts was also found to be dose dependent.
Non-enzymatic glycosylation of hemoglobin The results in our in vitro study depicted that inhibitory activity of methanol extract of watermelon and pomegranate peels on hemoglobin glycosylation was up to $61 \%$ and $55 \%$ respectively over a period of $72 \mathrm{hrs}$ at a concentration of $100 \mu \mathrm{g} / \mathrm{ml}$ with an IC50 values $83.21 \mu \mathrm{g} / \mathrm{ml}$ and $91.4 \mu \mathrm{g} / \mathrm{ml}$ respectively. They were significant when compared to the standard acarbose which possessed 76\% inhibition of hemoglobin glycosylation. Glycosylated hemoglobin inhibition percentage of 74 at a concentrated of $1000 \mu \mathrm{g} / \mathrm{ml}$ was reported in Pithecellbium dulce fruit peel extract (Kumar, 2015).

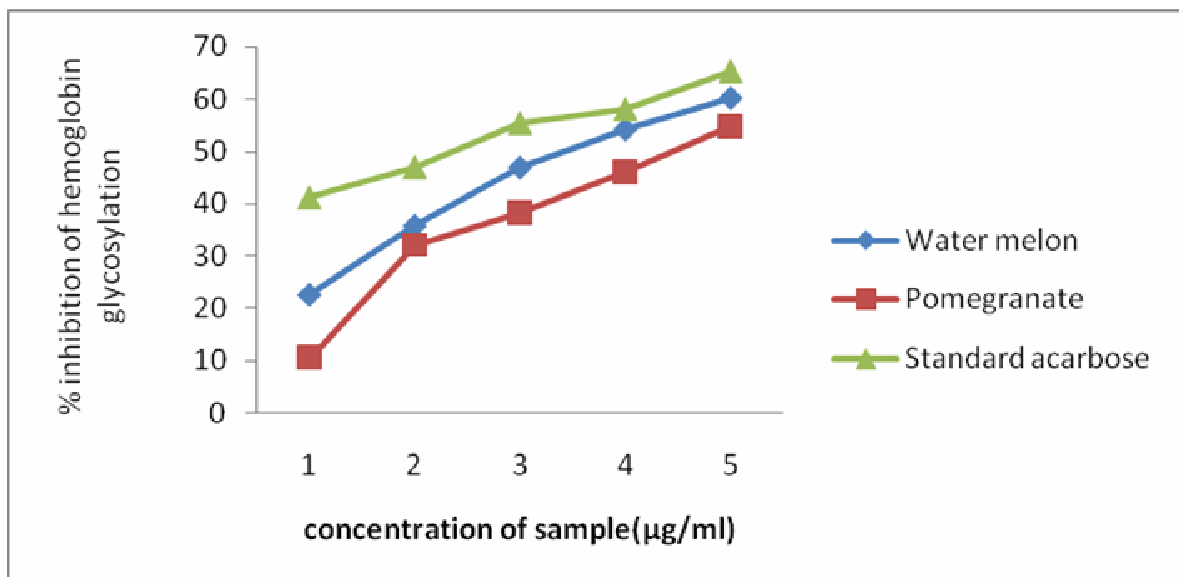

Figure 2: Inhibitory effect of methanol extract of watermelon and pomegranate peels on hemoglobin glycosylation in comparison with standard acarbose

\section{CONCLUSION}

The results of the current in vitro study suggest that the peel of Citrullus lanatus and Punica granatum were significant in inhibiting the activity of carbohydrate digesting enzyme aamylase and glycosylation of hemoglobin in comparison with standard acarbose. Thus Citrullus lanatus and Punica granatum can be considered an efficient source of bioactive compounds. However further mechanistic studies are needed to prove the effect in vivo. ACKNOWLEDGEMENT

The authors express their gratitude to Armat Biotek Research Institute Guindy, Chennai, India 


\section{REFERENCES}

Bastaki, S. (2005). Review Diabetes mellitus and its treatment. International Journal of Diabetes \& Metabolism 13:111-134.

Daksha, G., Chandrashekar, L. R., Yogendra and Nilesh, G. (2012). In-vitro Antidiabetic activity of stem bark of Bauhinia purpurea Linn. Scholars research library. 4(2):614-619

King H., Aubert R.E and Herman W.H. (1998). Global burden of diabetes, Prevalence, numerical estimates and projections. 2(1):1414-31.

Kitabchi A.E.,Umpierrez G.E., Miles J.M and Fisher J.N. (2009). Hyperglycemic crises in adult patients with diabetes. Diabetes Care. 32 (7): 133543.

Kumar, P. S. (2015). In vitro antidiabetic activity of compounds from Pithecellobiumdulce fruit peel.International Journal of Pharmaceutical Chemistry. 5 (4):125127

Nair, S. S., Kavrekar, V. and Mishra, A. (2013). Evaluation of In Vitro Anti diabetic Activity of Selected Plant Extracts. International Journal of Pharmaceutical Science Invention, 2(4):12-19

Poojari, S., Porika, R. and Mamidala, E. (2014). Phytochemical Analysis and In Vitro Antidiabetic Activities of Physalis angulata Fruit Extracts. National Journal of Integrated Research in Medicin. 5(2):34-38
Shi, Yuankai and Hu, Frank B. (2012). The global implications of diabetes and cancer, 2012. The Lancet . 383 (9933): 1947-8.

Vos, T., Flaxman A.D., Naghavi M., Lozano, R., Michaud, C., Ezzati, M., Shibuya K., Salomon J.A., Abdalla S., Aboyans V., et al. (2012). Years lived with disability (YLDs) for 1160 sequelae of 289 diseases and injuries 1990-2010: a systematic analysis for the Global Burden of Disease Study 2010. The Lancet. 380 (9859): 2163-96.

Kim J.S, Kwon C.S. and Son K.H.(2000). Biosci Biotech Biochem, 64, 2458.

Abirami N, Natarajan B and Sagadevan E. ( 2014). Phytochemical investigation and in vitro evaluation of hypoglycemic potential of Grewia hirsuta. Int $J$ Pharm Bio Sci. 5(1):76 - 83.

Dineshkumar B., Analava M. and Manjunatha M. (2010). A comparative study of alpha amylase inhibitory activities of common antidiabetic plants of Kharagpur. Int $\mathrm{J}$ Green Pharm. 4: 115-21

Pouryazd N. M.T. and Far T. A. (1995). Production of Vegetables Seeds, DejahadDenshgahi Press of Mashhad (in Persian language), Iran. pp. 50-69

Tariq Ismail, Piero Sestili and Saeed Akhta (2012). Pomegranate peel and fruit extracts: A review of potential antiinflammatory and anti-infective effects. Journal of ethnopharmaclogy. 143(2):397-405. 